\title{
Ivalonを用いた䯣膜腫に対する人工塞栓術
}

\author{
小池 哲雄・佐々木 修・石井 鏡二・田中 隆一・伊藤 寿介*・尾崎建二郎 ${ }^{* *}$ \\ 新井 弘之**.亀山 茂樹***. 谷村 憲—***
}

\section{Transcatheter Embolization with Ivalon Particles in Cases of Intracranial Meningiomas}

Tetsuo KoIKe, Osamu Sasaki, Ryoji Ishir, Ryuichi Tanaka, Jusuke Ito*, Kenjiro OzaKi**, Hiroyuki AraI**, Shigeki KameYAMA*** and Kenichi TANIMURA***

Department of Neurosurgery, Brain Research Institute, Niigata University, and ${ }^{*}$ Department of Oral Radiology, Niigata University School of Dentistry, Niigata; ${ }^{* *}$ Department of Neurosurgery, Kuwana Hospital, Niigata; ***Depariment of Neurosurgery, Sannocho Hospital, Sanjo, Niigata

\begin{abstract}
Experiences of preoperative embolization using Ivalon (polyvinyl alcohol foam) particles in 12 cases of intracranial meningiomas are reported. Preoperative embolization was carried out for the purpose of decreasing bleeding from the tumor during operation.

Catheterization was performed through the femoral artery in 8 cases and through the common carotid artery in 4 cases. Ivalon particles, with a mean size of $0.5 \times 0.5 \times 0.5 \mathrm{~mm}$, were instilled, half-and-half with normal saline and contrast material. The emboli were injected as gently as possible under the image intensifier.

In 9 cases a computed tomography scan was done after the embolization and all the cases showed a decrease in the contrast enhancement of the tumor. The operations were performed from 1 to 22 days after the embolization. Total removal was performed in 11 cases. The pathological specimens showed fragments of Ivalon within the tumor in 7 cases. In all the cases but one, the primary purpose of minimizing bleeding during operation, was achieved. No major side effects were encountered in this series. However, attention should be paid to vascular anomalies, such as the ophthalmic artery arising from the middle meningeal artery and the vertebral artery visualized through the collateral from the occipital artery, before embolization so as to prevent possible catastrophes.
\end{abstract}

Key words: intracranial meningioma, embolization, Ivalon

\section{I はじめに}

頭蓋内骵膜腫の手術成績は，CT などの X 線機器の開 発・進少により早期発見㧍よび正確な部位診断が可能にな ったこと，また手術顕微踥を含めた于術器具の改良などに

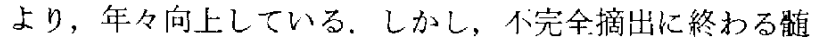
膜腫もいまだまれで仕ない、この良性腫瘄の摘出乎術に際 しては，その大きさや局在はむらろん，術中の出血処理が 手術の成否の鍵老握ると思われる，従来上り，この術中出 血の減少を目的として外頸動脈の結紮が行われてきたが，

\footnotetext{
新潟大学脑研究所脳神経外科 ${ }^{*}$ 同歯学部放射線科 **桑名病院脳神経外科 ***三之町病院脳神経外科

Address reprint requests to: T. Koike, M.D., Department of Neurosurgery, Brain Research Institute, Niigata University, 1-757 Asahimachidori, Niigata 951.
}

受稿 1984 年 3 月22日 受理 1984 年10月 1 日 
出血の著明な减少を得ることが困躍なこと，さらには外䜖 動脈を㩘牲にしてしまうことは問题である。近年，X線 機器の改良や血管造影手技の進少に伴い，外頸動脈采を市 な栄盖血管と寸る本腫場に対し，術中出血の減少省目的と して選抧的 catheterization 下に人工的塞栓術 (embolization) 在行い，比較的良好な成縝が得られている。これま での報告では，寒栓材料(emboli)上して gelfoam 名用いて いることが多い.Gelfoam は操作性が良く加工しやすい仅 面，比較的容易に尘体に吸收され栓寒血管の再開通が知時 日に起こり，したがって embolization 施行後は速やかに根 治手術を行う必紧がある゙ ${ }^{5,14)}$ ，最近我々は， emboliとして gelfoam と比べて操作性や加上性ではやや劣るものの, 非 吸仪性であるIvalon（polyvinyl alcohol foam)に着目し検討 を行ってきた，本稿ではこれまでの㪕告上比較しつつ，頙 盖内璡膜腫に対する Ivalonを用いた embolizationの効果 を，脳血管造影やCT 上の变化，術中所見さらに腫瘍の組 織学的变化などより㛟討し，若下の文献的考察を加える，

\section{II 対象および方法}

対象は，新潟大学脳神経外科抢上び関連施設に入院した

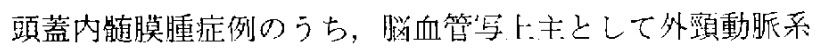
より血流供給を受ける12症例である。性別は男性 5 例，女 性 7 例で，年、秢は30〜78才である。発生部位は门盍部 4 例, 傍矢状洞 3 例, 大脸鎌 1 例, 蝶形骨隆起 1 例, 中頭蓋 窝 1 例，後頭蓋窝 2 例である. Embolization は 8 例に対し $\tau$ transfemoral, 4 例に対して transcarotid catheterization で行った。 Catheter は Becton-Dickinson 社製で外径0.062 インチ $(1.57 \mathrm{~mm})$, 内径0.045インチ $(1.14 \mathrm{~mm})$ で先端を 0.032 インチ $(0.81 \mathrm{~mm})$ に細くしたものを朋いた，Cath-

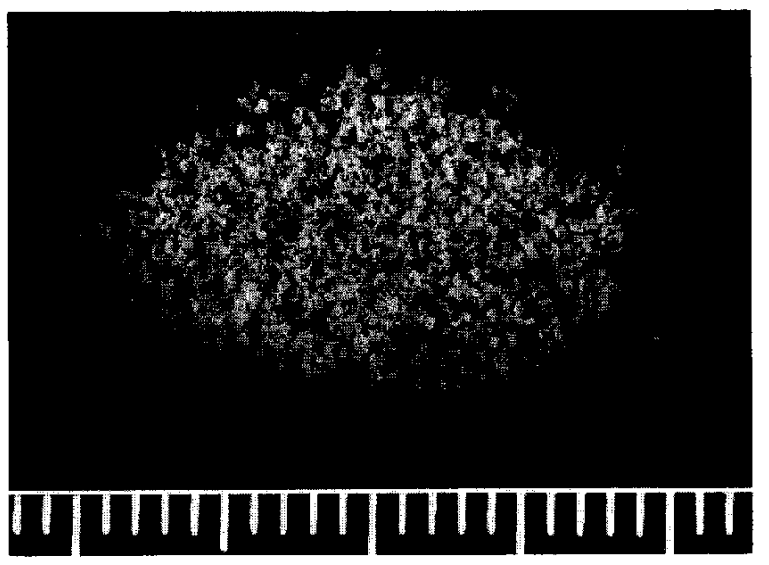

Fig. 1 Ivalon (polyvinyl alcohol foam) particles used as emboli in the dry state. The mean size of the emboli is $0.5 \times 0.5 \times 0.5 \mathrm{~mm}$ in the wet state. eterization で目的とする外頸動脈分枝にできるだけ選抧的 な挿入を計った。 Emboliとして用いたIvalon は，平均 $0.5 \times 0.5 \times 0.5 \mathrm{~mm} \sigma$ 細粒 (Fig. 1) にして造影剂 (Angio-

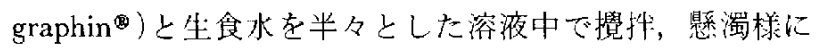
し, $5 \mathrm{ml}$ のディスポーザブル注射器で腫揚陰影の消失圭 みるまで繰り返し血流にのせて注入した。

\section{III 結 果}

以下に症例を呈示する。

<症例 $2>30$ 才, 男性, left frontal convexity meningioma

痤攣発作をもって発症したが，初診時神経学的な異常を 認めなかった。CTにて，左前頭葉に著明な contrast enhancement(堌強)を示寸腫瘍を諗めた。脳血管造影で は, left middle meningeal artery を主な feeding artery とす る tumor stain が出現し，典型的な sun-burst appearance を示していた(Fig. 2A)．Embolization中, emboli の浅側 䫓動脈一の流入を防ぐため用手的に同血管の圧迫を行つ た。 Embolization 後14日目の外頸動脈写では, feeding artery 浣全に閉塞し tumor stainの出現はみられなかっ た(Fig. 2B)。手術は embolizationの22日後に行われた。 Meningeal artery は虚脱し，硬膜付着部や腫瘍奏質加らの 出血虫きわめて少なく，腫愓は無理なくen blackに摘出し えた。病理学的検索では腫痬の各所に小壊死巣がみられ， 腫瘍内血管に hematoxylin に濃染する Ivalon が琹为られた (Fig. 3).

<症例 $5>70$, 女性, right frontal parasagittal meningioma

左片麻疩をもって無症し，CTで homogeneousに堌強さ れる腫瘍を右前頭葉正中部に認めた（Fig. $4 \mathrm{~A})$ ）兴血管造 影にてト記と診断し，feeding arteryである right middle meningeal artery $\omega$ embolization を行った. Embolization $5 \mathrm{H}$ 㣪の CT では，辽縁部を残し堌強病変は消头していた (Fig. 4B)，于術は embolizationの8 日後に行われたが, 腫瑒の硬膜付着部からの出血はなく, その讱䋑を除く大部 分流死に陥り，吸引除去可能であった。病理学的検索に おいても腫㩧の広沉な壤死を涊めた。

<症例 $8>71$ 才, 父性, right occipital parasagittal meningioma

知能障害・視野障责をむて発症L，GTで右後頭葉正 中部に著明に homogeneousに堌強される下大な腫瘍が認 められた(Fig. 5A)。両側 middle meningeal artery 後枝と left occipital arteryを feeding artery とする tumor stain 認 め，上記と診断した。同日，feeding arteryに对して embolization 施行した。 Fig. 5B 注施行 2 日後の CTである 

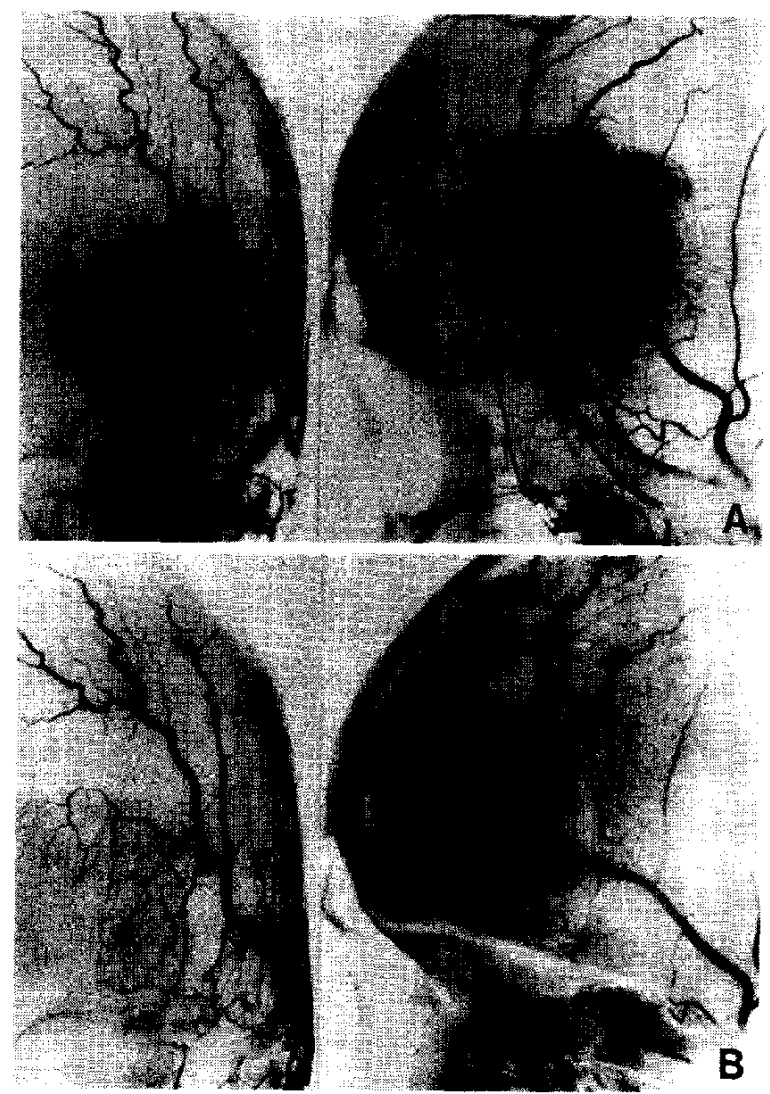

Fig. 2 Case 2, left frontal convexity meningioma. A: Pre-embolization. The anterior branch of the middle meningeal artery becomes thicker in the distal portion and supplies the tumor. A tumor stain of sun-burst appearance can be seen. B: Post-embolization. The middle meningcal artery is occluded and the tumor stain cannot be visualized. The superficial temporal artery is opacified.

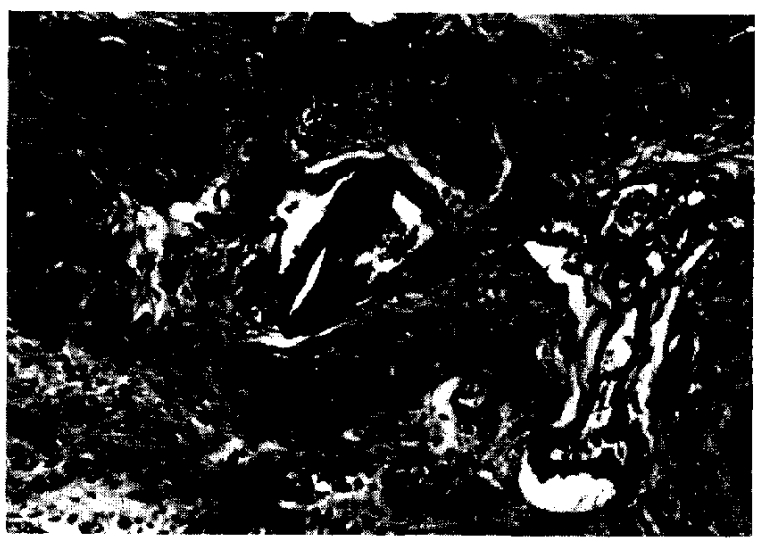

Fig. 3 Case 2. Photomicrograph of the embolized meningothelial meningioma. The presence of Ivalon in the arterial lumen of the tumor can be seen. HE stain, $\times 100$.
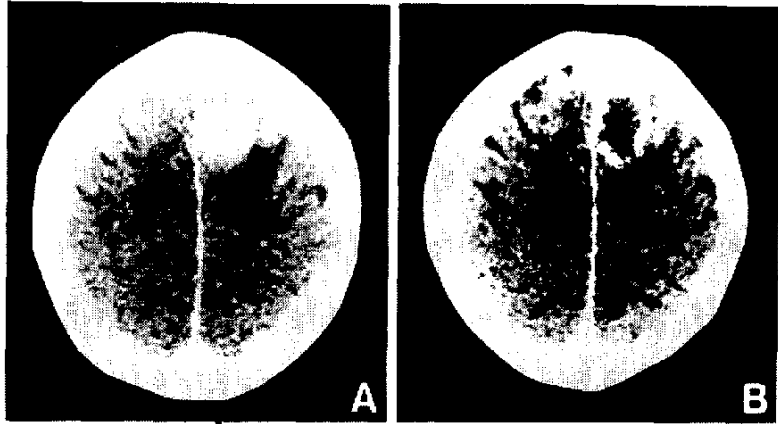

Fig. 4 Case 5. Right frontal parasagittal meningioma on computed tomography with contrast medium enhancement. A: The tumor is homogencously and highly enhanced before embolization. B: The tumor is inhomogeneously cnhanced only on the periphery after embolization.
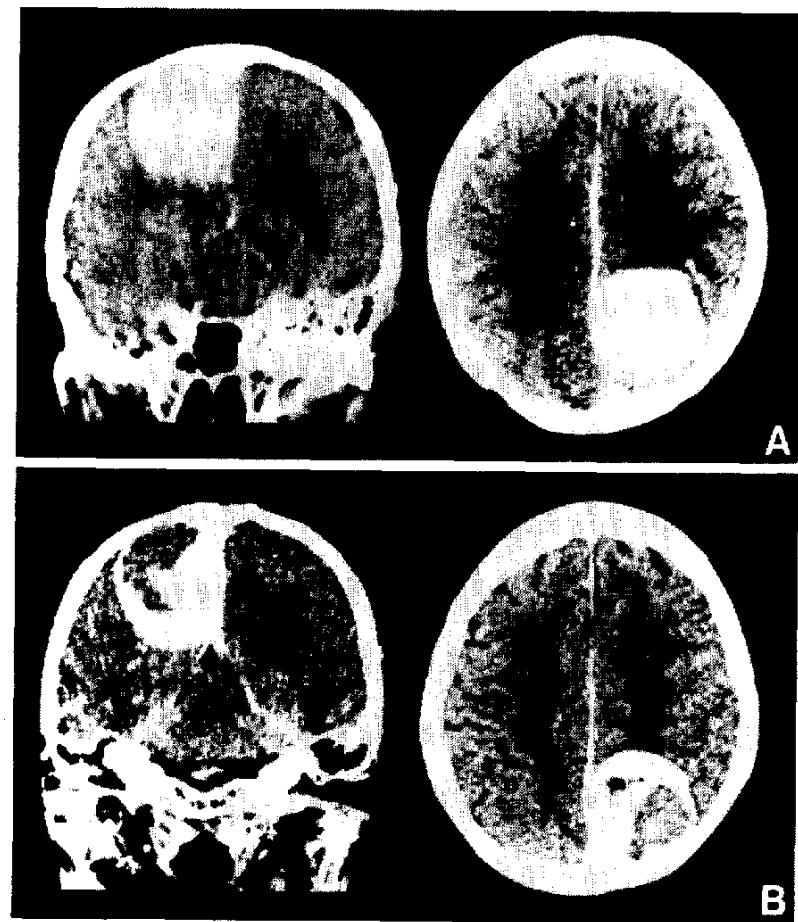

Fig. 5 Case 8. Right occipital parasagittal meningioma on computed tomography with contrast medium enhancement. A: The turnor is homogeneously enhanced before $\mathrm{cm}^{-}$ bolization. B: The convex side of the tumor is partially enhanced after cmbolization. The mass effect of the tumor is unchanged.

が，円蓋部を中心に增強されない部分が层籁国に出垷し た. 手術は embolization 後22日日に行われたが, 全経過を 通して出血は少なく，腫㳻は比較的容易に全摘出しえた。 病理学的検索汅て, 腫場队血管の血栓形成や広範䎴の腫晹 

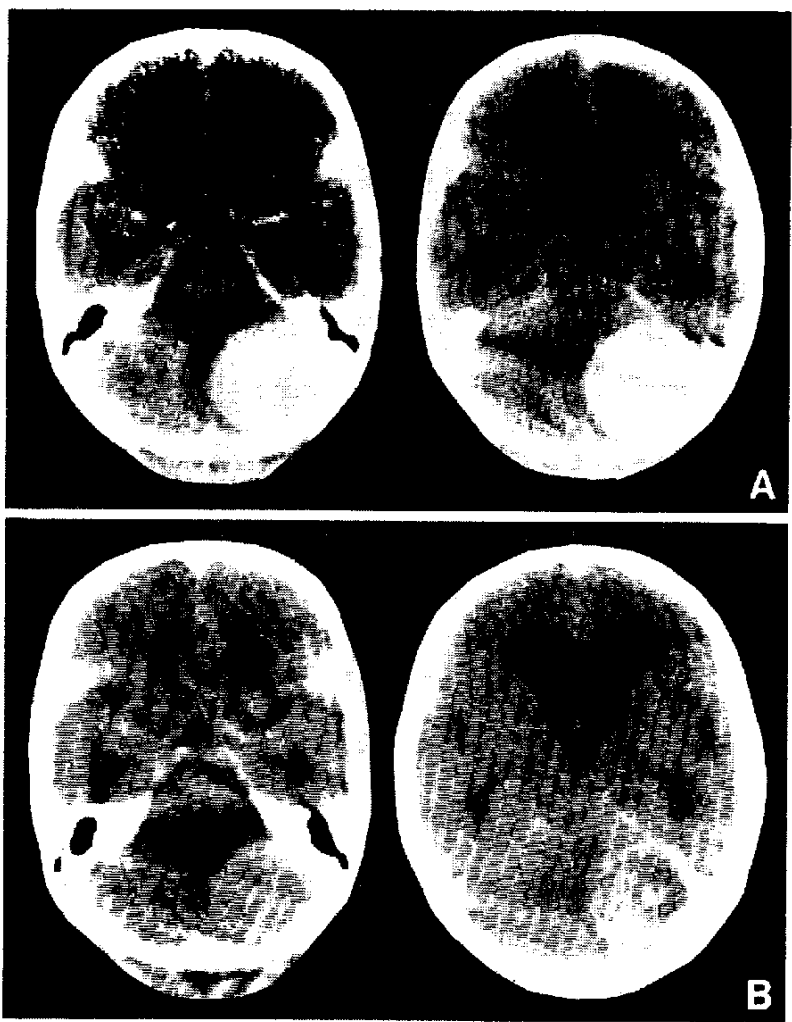

Fig. 6 Case 9. Right posterior fossa meningioma on computed tomography with contrast medium enhancement. A The tumor is homogeneously emhanced before embolization. B: The effect of contrast medium enhancement is obviously reduced after cmbolization.

壊死を贸的た。

<症例 $9>51$ 才, 文性, right postcrior fossa meningioma

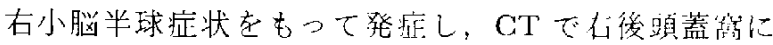
homogencousに堌強される大き栝揚を認め(Fig. 6A)， 脳血管造影で right occipital artery 先 feeding artery tumor stainが描出された(Fig. 7A)。Fig.7B は emboliza-

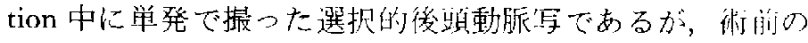
外頸動脈写ではみら扎なかった椎肖脳低動傆系が ○一 cipital artery の筋肉枝を介して描出された。る⿸たため。 の時点でまだわずかに tumor stain は残仔したが embolizationは中止した，施行後 5 口目のCTでは腫瘍の増強の程

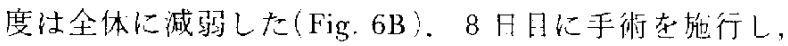
出血も少なく槛静脈洞部の硬膜に附着寸万腫瘍を全摘出し えた。

Table 1 K embolization 走行つた12证例をまとめた。 Enbolization で外頸動脈采の関与する tumor stain は〈症例 9〉 を除き消失しえた。 3 例(〈少例 $2 ， 4 ， 8\rangle$ において $\mathrm{embol}-$
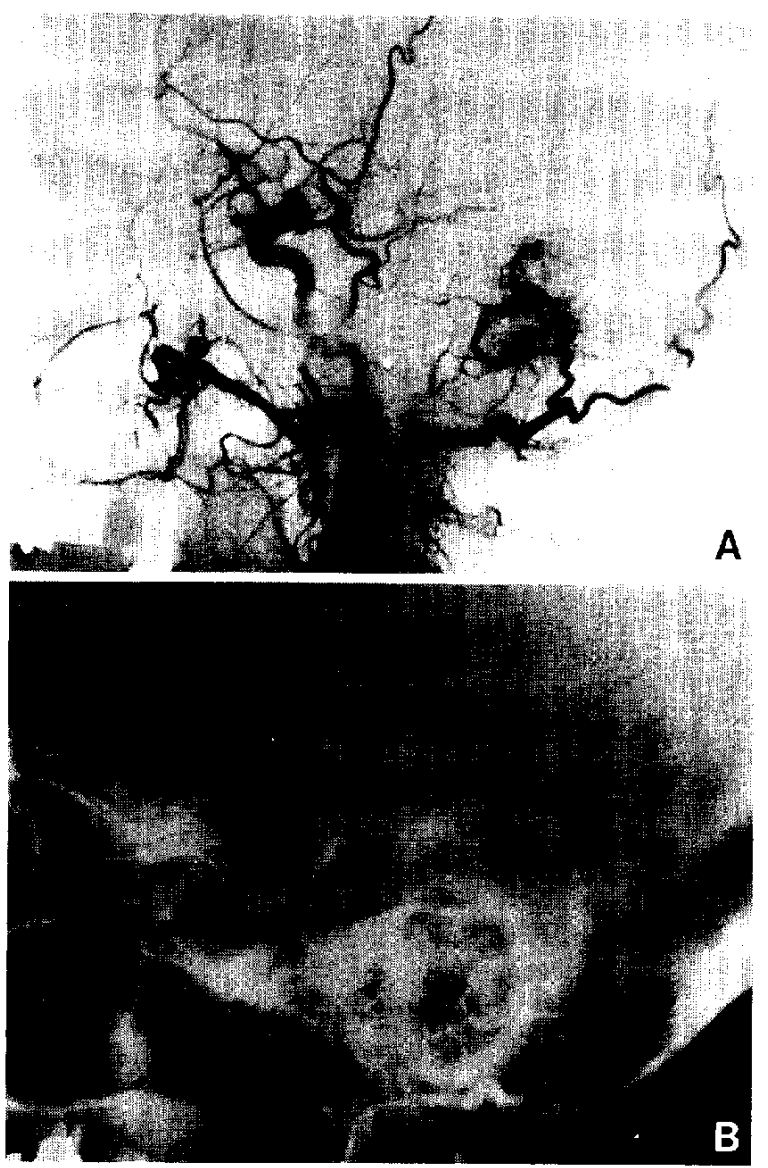

Fig. 7 Case 9, right posterior fossa meningioma. A: External carotid angiograph bcfore embolization. The right occipital artery supplies the tumor. B: Superselective external carotid angiograph after embolization. The tip of the catheter is located in the occipital artery. The tumor stain can be faintly visualized. The vertebro-basilar system is opacified through an occipito-vertebral collateral.

ization 後 フ〜14日目に脳盂管造影を施行したが，閉寒血 管の再開遇例はなかった。 また embolization 徭，9例で\} 術前にCTを施行したが， embolizationの効果と思われる 腫愓内増強病変の欠損あるいは減弱が全例に出現した。 の所見は embolization の翌日にCTを施行した2例〈泟例

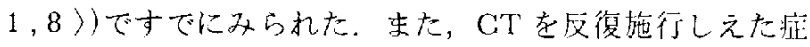
例のうち 2 例(〈作例 4，8〉)でこれらの变化が增大した。

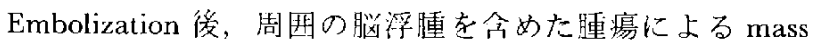
effect が強くなる例はなかった. Embolization から手術衣 では1〜22日であったが，手術時に閉寒血管の再開通をみ た症例はなかった。12例中11例に执いて，開䫓，硬膜処 理，腫掦摘出に際しての将血は，embolization 在行わない 
場合よりも明らかに少量であると思われ，5例において手 術時の輸近注要さなかった。〈症例 5 〉では, 腫瘍実質は大 部分吸引除去可能であった，11例でSimpson の分類いに よるIあるいは四の手術を施行しえたが，内頸動脈領域か らの feeding arteryもかなりみられた〈症例 7 〉では部分摘 出に終った。組織学的には Table 1 亿示す上うな組織像で あったが，種々の程度で embolizationに上ると思われる変 性壊死や䏦瘍内血管の血栓形成吉認めた，また， 7 症例て 摘出腫㨭内血管に emboli であるIvalon を確認しえた。

副作用としては，部分的な頙皮瀤死 1 例，頭痛 3 例，煩 部痛 2 例であったが，永続的あるいは重篤なものはなかっ た.

\section{IV 考察}

䯣膜腫に対する embolizationの効果としては，腫瘍 volumeの減少，臨术泟状改善の報告中もみられるが，術 中の腫瘍からの出血の減少がその主なものであろう. Emboli の種類や大きさは，これらのことを考虑して選拟する
必要がある，Picard ら9は，䏦瘍に対する embolizationの 効果として central tumor embolization, peripheral tumor embolization, さらに extratumoral embolization 上分類し，ま た伊藤ら ている、これまでの報告では，剈膜腫の embolization に用 いる emboli としては gelfoam が大多数を占める。 その大 きさとしては，Manelfe ${ }^{8:}$ D Dindjian ら ら $^{3.45} 10 \times 1 \times 1$

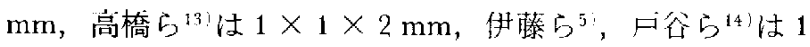
$\times 1 \times 0.5 \mathrm{~mm}$ と比洨的大きい。こ扎らの場合， $\mathrm{em}-$ bolization $の$ 効果位 tumoral embolization ${ }^{3 j}$ や embolization

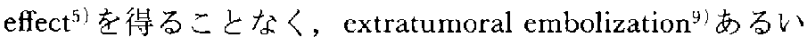
は ligation effect ${ }^{5}$ に終ることが多い上思われる。そのた め, 今回我々は tumoral embolization あるいは embolization effect 分得る目的加ら，emboli として細粒にし

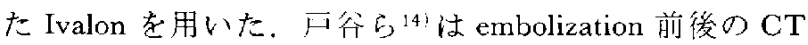
を比较し，6例中 2 例にのみ $\mathrm{CT}$ 上腫瘍の増強に变化がみ られたとしているが，我々の症例では embolization 後 CT を施行した全例に腄瘍内の虚侐変化思丸せる増強欠損部

Table 1 Summary of therapeutic embolization in 12 cases of intracranial meningioma

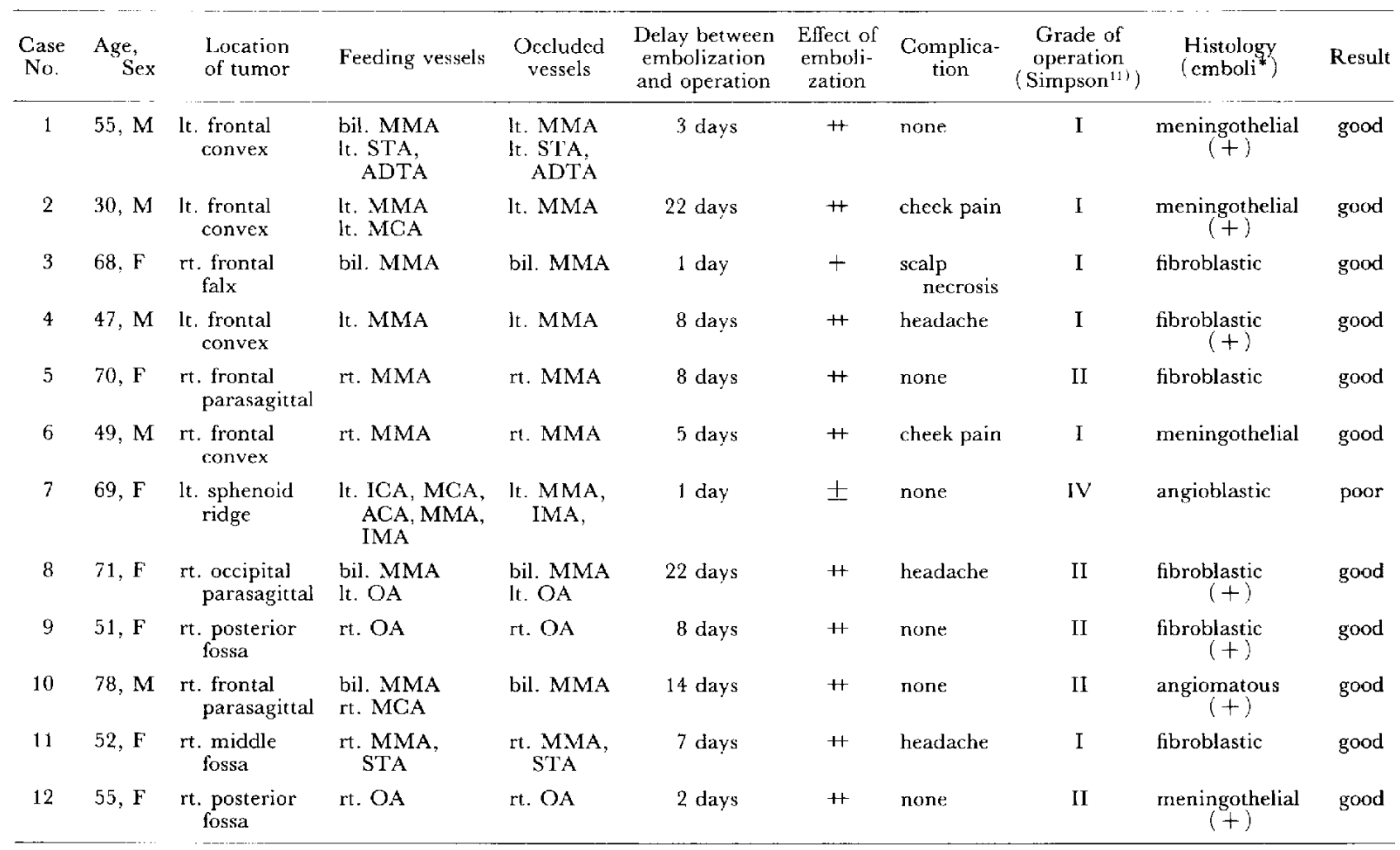

*Ivalon in the arterial lumen of the tumor. MMA indicates middle meningeal artery; STA, superficial temporal artery; ADTA, anterior deep temporal artery; IMA, internal maxillary artery; OA, occipital artery; ICA, internal carotid artery; MCA, middle cerebral artery; ACA, anterior cerebral artery; + , marked; + , moderate; \pm , minimum. 
やその減弱が出現した。また病理学的検势において摘出腫 碏の変性や壊死が多数にみられ，7例で 1 枚の標本比片中 の腫瘍内血管にIvalon を認めたことは，多数の emboliが 腫瘍内に存在することを示惨しており，従来の報告に比し さらに十分な tumoral embolizationが得られたと思われ た，以前当施設では，娟膜腫に対して gelfoam を用いた embolizationを行い報告しているう。 その結果と今回の Ivalon を用いたそれとの比較は，换討事項が異なること， また CUSAやlaserなどの手術器具の新たな導入なよ゙もあ り単純にはできない。しかし，両者の手術の大部分に携っ た我々の印象では，手術時の歫近減少効果は明らかに後者 が勝っていた．Emboli として gelfoamを册いた場合，柽 塞血管の再開通が比較的早期に起こるため, embolization 後できるだけ短時日に根治于術をする必要がある。今可 embolizationと手術までの間隔は最長22日であったが，全 例で手術時に桯塞血管の再開通は認めなかった。 したがっ $て$ ，Ivalon emboli として用いた場合，embolization と 摘出手術との時間的間隔をあまり考虑する必要はない上思 われる。また，前述のごとく Ivalon は gelfoam と比べ操 作性や加工性に扔いて少るが，永続的な血管閉塞が叮能で あるこ上は，高齡者や他将患合併者などの risk factor $の 人$ きい症例に対し，embolizationで腫瘍の壊死を計り， mass effectを減ずることなどにより外科的治療の一部代用 をなす可能性を示唆していると思われる.

今回は embolizationによる合併症として重篤なまた不叮 逆的な怔例を経験しなかったがここれまで钼動脈への emboli の流入などの合併症も報告されている11,4, 。 Gelfoamでももちろんであるが，非吸收性の Ivalon を用 いた場合はいっそうその合併症の発生には注意索払う必奖 がある。できる限り目的血管に selective catheterization を 行うことは必須であり，そのため今回 transfemoral では十 分な catheterizationができなかった4虚例に対しては transcarotid で目的血管に catheterization 走行った，また，後顽動脈を feeder とする例(〈证例12〉) では十分な catheterization をしえず，同血管が頸動脈分岐 部に近く emboli $の$ 内頸動脈への流入の危険が大きいため, embolization に際して balloon catheter 用いて队项動脈 血流を一時遮断した，Embolizationに際しては，溶液より 軽く踈水性である Ivalonの性質を考慮して注人直前まて 十分攪挥すること，透視下で emboli を血流にのせて汗入 すること，さらに embolizationがある程度なされ血流が遅 延してきた時期にはいっそう慎重に emboli 在注入するこ となどに留意した。

髁膜䏦に対する embolizationの場合，続いて摘出手術が なされるため，頭皮壞死を予防する意味から浅側頭動脈を
温存することは重要である。高橋ら131は浅侧頭動脈老温存 することが必装な症例に対し，教血的に同血管を露出し一 時血流を遮断して embolization 索施行したと述べている。 我々は，embolization中用于的に浅側頭動脈厈迫するこ とで emboli の流入老最小限にしえた。本法施行に際して は，眼動脈が中硬膜動脈から血流を受けるvariation ${ }^{1,2,7\}}$ や，後頭動脈上椎骨動脈との等肉枝を介寸る吻命46,10,12)の 有無などを常に考慮する必要がある。〈症例 9 〉たいて， 術前の外頸動脈造影では传頭動脈と椎骨動眽上の吻合は認 めえなかったが，選扑的に後頭動脈人 catheterization Lて embolization を隹めるうちに同吻合がみられたため同手 技を中断したように，血流動態が embolizationにより変 化していくことも念頭に置き手抆を進めるべきと思われ る。

\section{$\mathrm{V}$ ま め}

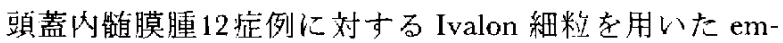
bolizationの経験を述べた。

1. Emboli として Ivalon 細粒を用いることにより，手 術時の壮血減少などの embolizationの効果はこれまでの gelfoam などによる報告に比して明らかに増大した。

2. 重篤な副作用はみられなかったが，本法施行に際し ては血管の anomaly が存在することに常に留意する必要 がある。

\section{文献}

1) Brismar J, Cronquist S: Therapeutic embolization in the external carotid artery region. Acta Radiol (Diagn) (Stockh) 19: $715-731,1978$

2) Brucher J: Origin of the ophthalmic artery from the middle meningeal artery. Radiology 93: 51-52, 1969

3) Djindjian R, Cophignon J, Theron J, Merland JJ, Houdart R: Embolization by superselective arteriolography from the femoral route in neuroradiology. Review of 60 cases. Neuroradiology 6: 2026,1973

4) Djindjian R, Merland JJ: Superselective Arteriography of the External Carotid Artery. Berlin, Springer, 1978, 75 pp

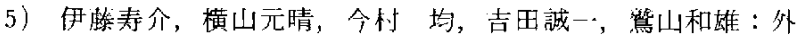
頸動朊領域における embolization の経駼。祭神外科 8: 11451153,1980

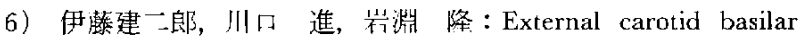
anastomosis 01 例. 脳神外科 3: 429-434, 1975

7) Lombardi G: Ophthalmic artery anomalies. Ophthalmologica (Basel) 157: 321-327, 1969

8) Manelfe C: Transfemoral catheter embolization of the intracranial meningiomas, in Salamon $\mathrm{G}(e d)$ : Advances in Cerebral Angiography. Berlin, Springer, 1975, pp 184-191

9) Picard L, Robert J, Andre JM, Montaut J, Roland J, Sigiel M, 
Gengler L, Lepoire J: Embolization with iodine 131-market Spongel technique, indication and results. $J$ Neuroradiol 3: 53-74, 1976

10) Schechter MM: Occipital-vertebral anastomosis. J Neurosurg 21: $758-762,1964$

11) Simpson $\mathrm{D}$ : The recurrence of intracranial meningioma after surgical treatment. J Neurol Neurosurg Psychiat 20: 22-39, 1957

12）高橋 弘, 山山昂一, 上村一夫, 古和田正悦, 松岡茂, 伊藤善太郎: Occipit-vertebral anastomosis 04 症例。脳上神 23: 1315-1319, 1971

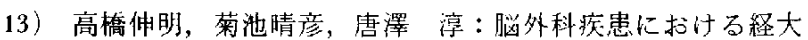
腿カテーテル塞栓術。脳神外科 11:591-602, 1983

14）号谷重雄，㷪原隆造，上田守二，市来峆潔，秋山武仁，四 宮陽一，石山值已，岩田隆信，志賀适夫，柳下 章，向井方 起男：髄膜腫 6 例に扮ける腫場栄盖血管カテーテル栓塞術. Neurol Med Chir (Tokyo) 18 [Part II ]: 803-811, 1978

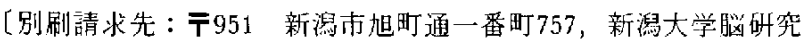
所脳神経外科，小池哲雄了 